\title{
Incidência de lesões cutâneas em um rebanho ovino no município de Rio Bonito, RJ Brasil
}

\section{(Cutaneous lesions incidence in a sheep flock in Rio Bonito Rio de Janeiro State, Brazil)}

\author{
BORGES, José Renato Junqueira**, SANTOS, Orlei Justen dos ${ }^{\star \star}$, TORTELLY, Rogério*** BANDOLI, \\ José Geraldo ${ }^{\star \star \star}$, LESSA, Daniel A.B. ${ }^{\star \star \star \star}$, SOARES, Claudia S. ${ }^{\star \star \star}$ SILVA, Laura C.S. ${ }^{\star \star \star *}$
}

\section{RESUMO}

Um rebanho ovino no Município de Rio Bonito, Estado do Rio de Janeiro constituído de 144 animais, a maioria com pele despigmentada e com pelagem branca, apresentou alto índice de dermatite crônica $(32,6 \%)$, carcinoma epidermóide (9\%) e cisto epidermóide $(4,7 \%)$. O carcinoma epidermóide foi observado em fêmeas adultas sendo quatro com localização na pálpebra, cinco na orelha, duas no focinho e duas no abdômen. O cisto epidermóide foi observado em 7 fêmeas deslanadas com mechas ralas, com localização cervical, torácica e abdominal. As lesões de pele foram diagnosticadas através do exame clínico e histopatológico. Cem por cento dos animais deslanados com mechas ralas apresentavam lesões de pele, sendo que 20 apresentavam mais de um tipo de lesão.

A alta incidência de lesões de pele foi atribuída à exposição prolongada ao sol de animais despigmentados e sem uma boa proteção, devido a falta de densidade da lã, no caso dos deslanados com mechas curtas e ralas. A região apresenta insolação alta, associada às pastagens de grama nativa sem presença de sombreamento. A medida profilática adotada foi o descarte dos animais com lesões em estágios adiantados e dos reprodutores, substituindoos por animais pigmentados. Quatro anos após, a presença de animais com lesão de pele é mínima.

Palavras-chave: Lesões epidermicas - ovinos.

\section{Introdução}

As fotodermatites são divididas em quatro tipos sendo duas de maior interesse: as queimaduras pelo sol, com desenvolvimento de dermatite crônica, causadas pelos raios ultravioletas (UV) do tipo B com o espectro de 290 a 320 nanometros $(\mathrm{nm})$ de comprimento de onda e a fotossensibilização causada pelos raios UV tipo A com 320$400 \mathrm{~nm}$ de comprimento de onda. O primeiro tipo é causa- do pela ação direta dos raios solares sobre a pele e o segundo há a necessidade da pele apresentar uma sensibilidade maior aos raios UV-A (Scott, 1988).

Outra lesão de pele associada a exposição prolongada aos raios solares é o carcinoma epidermóide (Scott, 1988 e Scott, 1993) sendo que em alguns casos pode ser originado de cistos. As lesões ocorrem mais comumente nas oreIhas, lábios, focinho, pálpebras e região perineal (Riet-Correa et al., 1981 e Scott, 1988).

O objetivo deste trabalho foi diagnosticar e levantar a ocorrência de lesões cutâneas em um rebanho ovino no Município de Rio Bonito, Estado do Rio de Janeiro, discutir sua etiologia e indicar medidas profiláticas.

\section{Material e Métodos}

Foram estudadas, em novembro de 1988, diferentes lesões cutâneas em um rebanho ovino de uma propriedade no Município de Rio Bonito, RJ. O Município apresenta topografia plana a semi-plana, clima tropical úmido, com latitude sul $22^{\circ} 42^{\prime} 4^{\prime \prime}$ e $42^{\circ} 37^{\prime} 6^{\prime \prime}$ de longitude W G12 e altitude de $51 \mathrm{~m}$.

O regime de criação era extensivo com piquetes compostos de gramíneas e sal mineral à disposição

O rebanho era constituído de 144 animais: 3 machos mestiços deslanados e despigmentados; 98 fêmeas adultas, sendo 38 deslanadas com lã densa, 35 deslanadas sem lã densa e 25 lanadas; e 43 jovens deslanados e lanados.

Procedeu-se o exame clínico de todos os animais observando-se o estado de saúde, a presença de lesões cutâneas, suas localizações e aspectos. Retiraram-se amostras para exame histopatológico de todas lesões cutâneas suspeitas de carcinoma epidermóide, de cisto epidermóide e dermatite solar crônica. O material coletado foi fixado em formol a 10\% e destinado ao Serviço de Anatomia Patológi-

\footnotetext{
* Resumo apresentado no XXIl Congresso Brasileiro de Medicina Veterinária, Curitiba, 1992

* Professores do Depto de Patoiogia e Clínica Veterinária da UFF.

*** Professores do Depto de Patologia e Apoio Clínico da UFF

$* * * *$ Médicos Veterinários
} 
ca Veterinária da Universidade Federal Fluminense, para a inclusão em parafina e coloração pelo Hematolina Eosina.

Dois animais, em que o estado geral não permitia a extirpação cirúrgica da tumoração suspeita de carcinoma epidermóide, foram sacrificados e necropsiados com a finalidade de se detectar possíveis mestástases.

\section{Resultados}

A Tabela I demonstra a incidência de dermatite crônica e sua distribuição segundo o sexo, faixa etária, tipo de pelagem e localização. Observou-se dermatite crônica generalizada em 100\% das fêmeas deslanadas sem lã densa. Nas fêmeas deslanadas com lã densa e lanadas, machos e jovens, as lesões se restringiram às áreas da orelha e ao redor do focinho, e a incidência foi baixa (Figs. 1 a 9).

A dermatite em sua fase inicial apresentava-se eritematosa, evoluindo para o aparecimento de pequenas máculas castanhas, como se fossem "sardas", e formação de crostas. Nos estágios mais avançados observavase a presença de conifícações isoladas ou em placas. Uma destas cornificações, com localização na orelha, já apresentava sinais de carcinoma epidermóide à histopatologia.
O exame microscópico de fragmentos de pele revelou atrofia da epiderme. As dermes papilar e reticular mostravam-se fibrosadas e discretamente infiltradas por mononucleares.

Foi observado maior incidência de carcinoma epidermóide (Tabela II) nas fêmeas deslanadas com lã densa e os jovens não apresentaram a lesão.

o carcinoma epidermóide apresentava-se como nodulação de consistência dura, tamanho variável e geralmente recoberta por crostas, que removidas evidenciavam a presença de úlceras que sangravam com facilidade. $\mathrm{Na}$ pálpebra, em sua fase inicial apresentava o aspecto papilar.

O exame microscópico do material obtido para biópsia ou do tumor extirpado revelava lesões tumorais constituídas por proliferação de células epiteliais, dispostas em camadas, agrupamentos sólidos ou cordões irregulares, centralizados, aqui e ali, por lâminas concêntricas de ceratina. A neoplasia infiltrava a derme papilar e reticular, chegando até as proximidades da hipoderme. As lesões mostravamse ulceradas e recobertas por material crostoso havendo em alguns casos, áreas de hiperplasia epitelial, papilomatosa, com nítida transformação malígna. Observa-

Tabela 1 - Incidência de Dermatite Crônica e sua distribuição segundo a faixa etária, sexo e localização da lesão em um rebanho ovino no RJ.

\begin{tabular}{lcccc}
\hline Idade (Qtdade) Mocal lesão & $\begin{array}{c}\text { Lombo } \\
\text { Dorso }\end{array}$ & $\begin{array}{c}\text { Orelhas } \\
\text { Ao redor do } \\
\text { focinho }\end{array}$ & $\begin{array}{c}\text { Total de } \\
\text { animais(\%) }\end{array}$ \\
\hline Machos (3) & - & 1 & 1 & $1(33,3)$ \\
Femeas & - & 3 & 3 & $3(7,9)$ \\
Deslanadas c/mechas densas (38) & - & 35 & 35 & $35(100)$ \\
Deslanadas c/mechas ralas (35) & -5 & 5 & 5 & $5(20)$ \\
Lanadas (25) & - & 3 & 3 & $3(7)$ \\
Jovens (43) & 35 & 47 & 47 & $47(32,6)$ \\
\hline Total (144) & 35 & & & \\
\hline
\end{tabular}

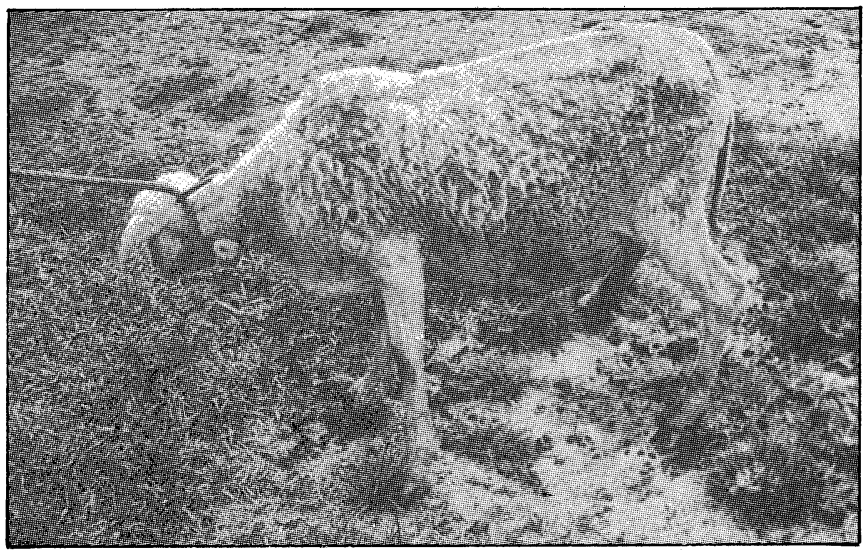

Fig. 1 - Aspecto geral de uma ovelha com dematite crônica.

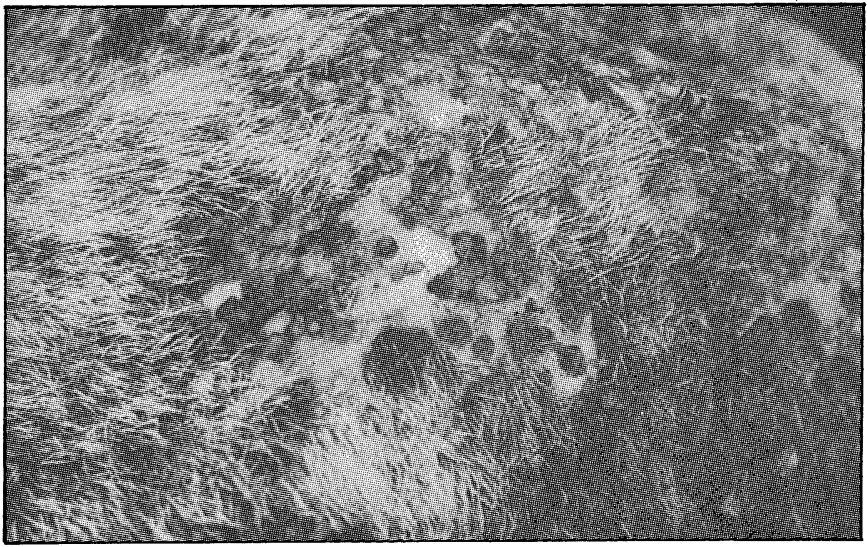

Fig. 2 - Dermatite crônica no dorso com areas de alopécia, pigmentação e formação de crostas. 


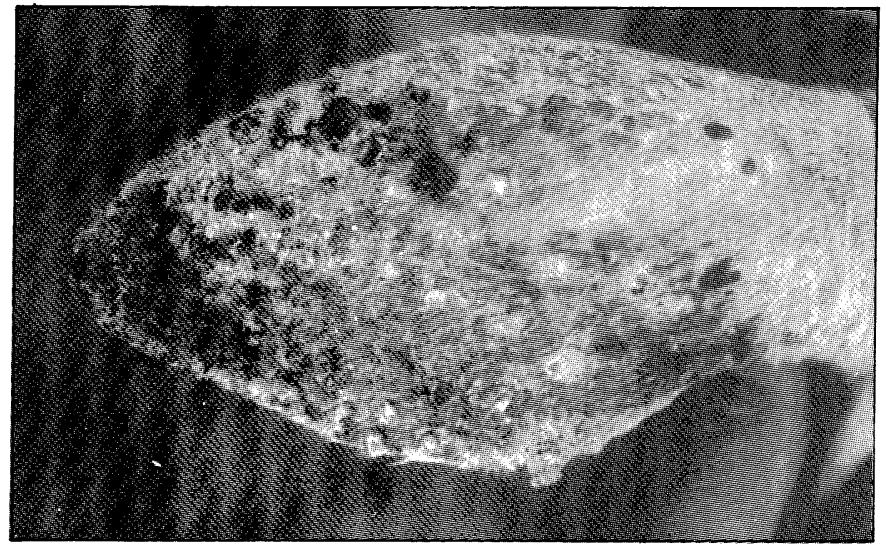

Fig. 3 - Dermatite crônica na orelha com áreas de alopécia, formação de crostas e cornificação.

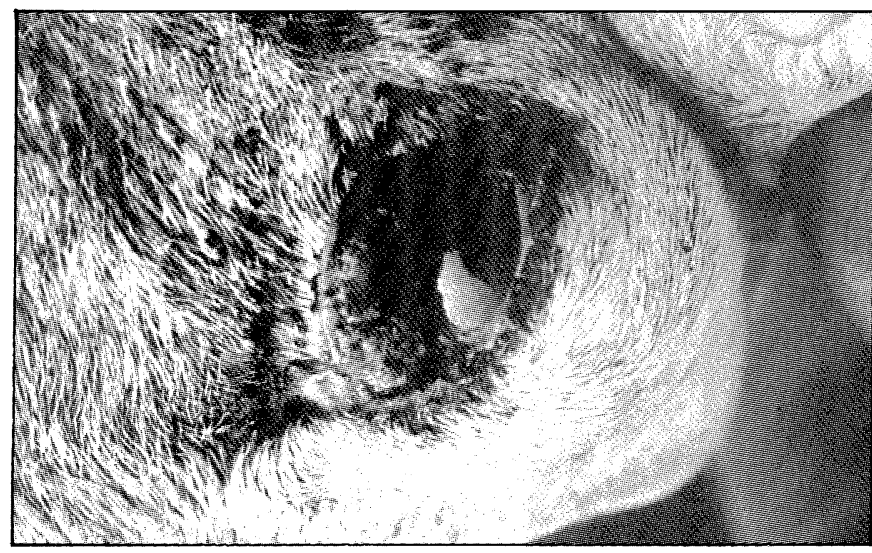

Fig. 5 - Carcinoma epidern. wa de pálpebra int in direita.

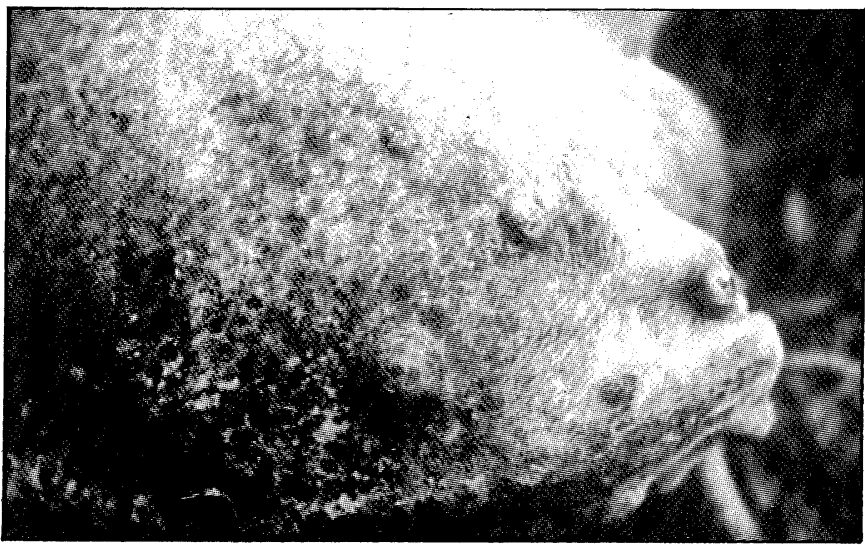

Fig. 7 - Cistos epidermóides em ovelha com dermatite crônica.

va-se, também, infiltrado representado principalmente por polimorfonucleares, neutrófilos e linfócitos.

Nos dois animais necropsiados não foram encontradas metástases

O cisto epidermóide foi observado em 7 fêmeas deslanadas sem lã densa, com localização múltipla: cervical, torácica, abdominal e faces externa e interna da coxa. O cisto que tinha o aspecto nodular de 1 a $6 \mathrm{~cm}$ de diâmetro,

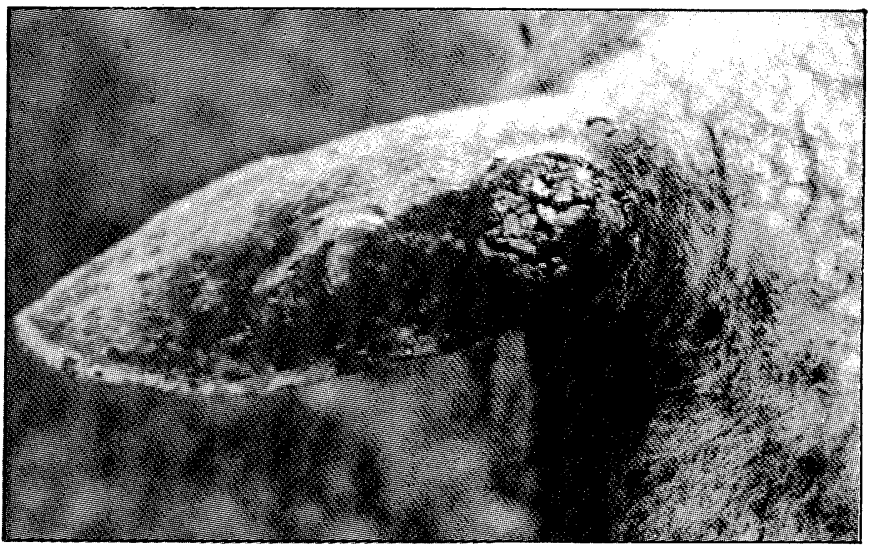

Fig. 4 - Carcinoma epidermóide na orelha

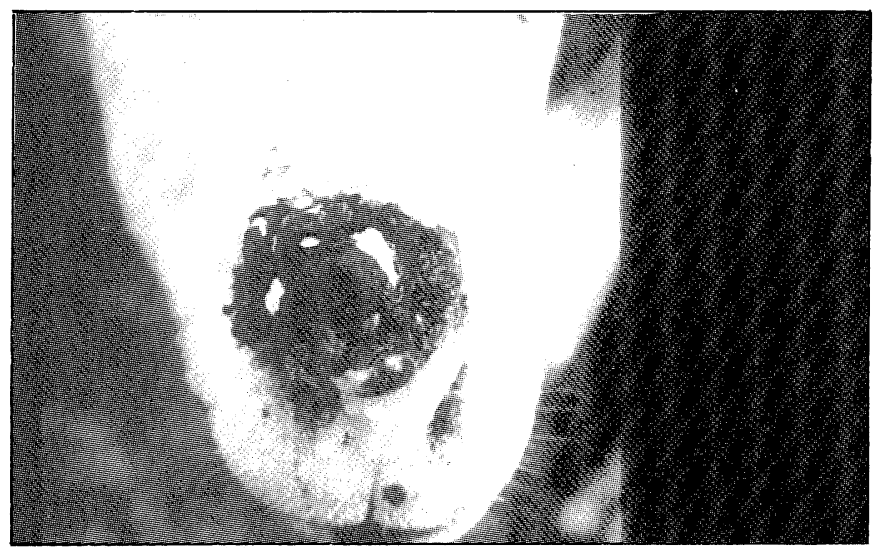

Fig. 6 - Carcinome.. lermóide de tocinho.

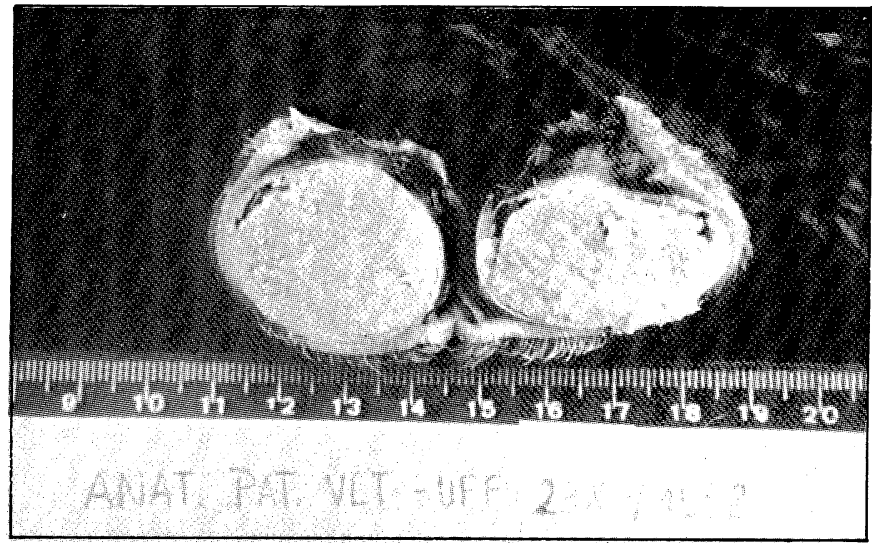

Fig. 8 - Aspecto do conteúdo de um cisto epidermóide.

era recoberto por pele, com sinais de dermatite crônica e apresentava certa resistência ao toque. Extirpado, a superfície de corte mostrava total preenchinento da luz por uma massa esbranquiçada e cremosa. O exame microscópico das nodulações revelou formações císticas revestidas por epitélio pavimentoso estratificado còm abudante produção de ceratina. As estruturas císticas mostravam-se envolvidas por tecido conjuntivo fibroso e discreto infiltrado inflamatório 


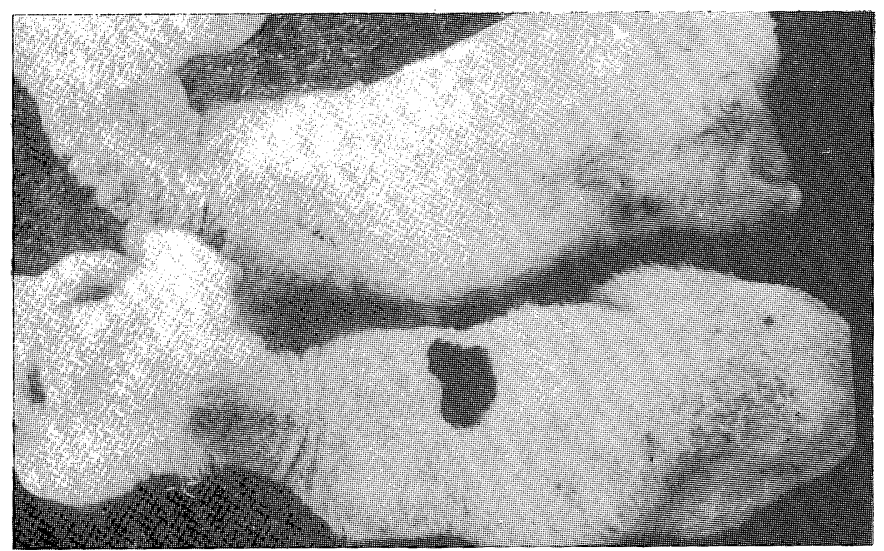

Fig. 9 - Felagem de dois ovinos jovens mostrando a ditèença entre pelagens dos animais que desenvolverão (inferior) ou não (superior) a dermatite crônica.

Tabela 2 - Incidência de carcinoma epidermóide em fêmeas de um rebanho ovino no RJ.

\begin{tabular}{lcc}
\hline $\begin{array}{l}\text { Local } \\
\text { Pelagem } \\
\text { (№) }\end{array}$ & $\begin{array}{c}\text { Deslanadas } \\
\text { Mechas ralas (35) }\end{array}$ & $\begin{array}{c}\text { Lanadas } \\
(25)\end{array}$ \\
\hline Palpebra & $2(5,71 \%)$ & $2(8 \%)$ \\
Orelha & $4(11,43 \%)$ & $1(4 \%)$ \\
Focinho & $1(2,85 \%)$ & $1(4 \%)$ \\
Abdomen & $2(5,71 \%)$ & - \\
\hline Total & $9(25,85 \%)$ & $4(16 \%)$ \\
\hline
\end{tabular}

Obs.: Incidência total no rebanho $(144)=13(9 \%)$

de mononucleares. $O$ revestimento epidérmico apresentava-se ligeiramente espessado e com freqüentes figuras cariocinéticas nas células das camadas mais profundas. Os elementos glandulares regionais estavam distorcidos e ligeiramente distendidos.

Cerca de 20 animais apresentavam mais de um tipo de lesão.

Os animais portadores de carcinoma epidermóide foram descartados, sendo introduzido no rebanho machos reprodutores deslanados com lã densa e pigmentados. Os animais portadores de cistos e dermatite crônica foram descartados paulatinamente. O rebanho foi acompanhado até novembro de 1992

Quatro anos após o índice de lesões epidérmicas é mínimo. O número de animais deslanados sem lã densa diminuiu consideravelmente, e continuam sendo descartados.

\section{Discussão e Conclusão}

A dermatite crônica por queimadura pelo sol tern sido descrita em suínos e caprinos em locais com pele despigmentada (Scott, 1988). Não há referências sobre sua existência nos ovinos. Nos caprinos, a pele do úbere tem sido a mais atingida (Scott e Smith, 1984 e Scott, 1993). No presente trabalho a maior incidência foi registrada na pele do focinho, da orelha, dorso e lombo. Borges et al., (1988) encontraram dermatite crônica no dorso de touro holandês vermelho e branco associado a carcinoma epidermóide de escroto e atribuíram estas lesões a insolação excessiva do norte do Estado do Rio de Janeiro, que apresenta insolação semelhante ao Município de Rio Bonito.

A ocorrência de carcinoma epidermóide foi maior na orelha, depois na pálpebra e por último, com dois casos respectivamente, no focinho e abdômen. Lloyd (1961) também encontrou maior inciência na orelha, entretanto Riet-Correa et al., (1981) em trabalho realizado no Estado do Rio Grande do Sul, observaram alto índice de carcinoma epidermóide no focinho. Silva e da Silva (1986) encontraram no Nordeste brasileiro incidência elevada de carcinoma epidermóide nas pálpebras de ovinos deslanados, mas não fazem referência à outras localizações, nem a outros tipos de lesões. Não foram encontradas referências ao aparecimento de carcinoma epidermóide no abdômen. O não aparecimento de carcinoma epidemóide no períneo, comum em vários países, está relacionado com a falta da prática da operaçăo radical de Mules na nossa região, na qual há o seccionamento da cauda, (Vandergraff, 1976)

A incidência de quase 13\% de carcinoma epidermóide em ovinos adultos pode ser considerada muito alta, principalmente em relação aos achados de 1,8\% de Riet-Correa et al., (1981).

O cisto epidermóide é encontrado raramente em ovinos, apresentando maior inciência em eqüinos (Scott, 1988). Lloyd (1964) relacionou um alto índice de cistos em ovinos com a penetração de sementes na pele. No presente trabalho não foi possivel relacionar o aparecimento dos cistos com qualquer fator desencadeante. Possivelmente, a insolação excessiva pode ter tido alguma influência, uma vez que o cisto epidermóide também tem sido observado em ovinos deslanados no norte do Estado do Rio de Janeiro, na mesma região onde Borges et al. . (1988) encontraram lesões de pele em touro holandês e atribuíram à alta insolação.

Não foi possível estabelecer uma relação entre cisto epidermóide e carcinoma epidermóide como citou Lloyd (1964).

A incidência elevada de carcinoma epidermóide e dermatite crônica foi atribuída à exposição prolongada ao sol de animais despigmentados e sem boa proteção. Esta devido, a falta de densidade da lã, no caso dos ovinos deslanados sem lã densa. Há autores que atribuem à exposição solar prolongada o surgimento do carcinoma epidermóide em diversas espécies (Jubb et al. , 1985; Scott, 1988). Isto fica bem evidenciado pelo fato da introdução de reprodutores pigmentados ter diminuído o índice das lesões epidérmicas.

\section{Summary}

\section{Cutaneous lesions incidence in a sheep flock in Rio Bonito Rio de Janeiro State, Brazil}

A flock with 144 sheep in Rio Bonito Rio de Janeiro state, (Brazil) showed high chronic dermatitis (32,6\%), squamous cell carcinoma (9\%) and epidermoid cyst 
$(4,7 \%)$ indexes. Squamous cell carcinoma was observed in adult females: four in the eyelids, five in thre ears, two in the snout and two in the abdomen. Epidermoid cyst was seen in seven wool-less female with sparse tufts. Its Iocation was cervical, thoracic and abdominal. Skins lesions were diagnosed by clinical and hostological examination. All wool-less animals with sparse tufts had skin lesions, among them 20 had more than one lesion. The high lesion incidence was attributed to extended sun exposition of animals without pigmentation and without adequate protection due to low wool density (in the case of wool-less animals). The region is highly insolated ahd has native pasture without shadowing. Culling males and animals with advanced stage lesions was the prophylactic measure adopted. Four years later, there has been minimal numbers of animals with skin lesions.

Key words: Epidermic Lesions - sheep.

\section{Referências Bibliográficas}

BORGES, J.R.J., CARVALHO, C.C, TORTELLY, R. Carcinoma epidermóide diferenciado na bolsa escrotal de touro holandes. In: Congresso Brasi- leiro de Medicina Veterinária, 21, 1988, Salvador. Anais. Salvador: Sociedade Brasileira de Medicina Veterinária, 198. p. 28

JUBB, K.V.F., KENNEDY, P.C., PALMER, N. Pathology of domestic animals 3ed. Orlando: Academic Press, 1985. $2 \mathrm{~V}$

LLOYD, L.C. Epithelial tumours of the skin of sheep. Brit. J. Cancer, v. 15, p. 780-789, 1961.

LLOYD, L.C. The aetiology of cysts in the skin of some families of Marino Sheep in Australia. J. Path. Bact. v. 88, p. 219-227, 1964.

RIET CORREA, F., CASSAL, A.B., SCARSI, R.M., SCHILD, A.L., MENDEZ, M.C. Carcinomas epidermóides em ovinos em um estabelecimento do Rio Grande do Sul. Pesq. Vet. Bras., v. 1, n. 2, p. 65-68, 1981.

SCOTT, D.W., SMITH, M.C. Caprine dermatology Part II. Viral, nutritional environmental and congenito hereditary disorders. Compend. Cont. Ed. v. 6, n. 8, p. 473-484, 1984.

SCOTT, D.W. Large animal dermatology. Philadelphia: Saunders, 1988. 487p.

SCOTT, D.W. Environmental skin diseases. In: Howard, J.L. (Ed.) Current veterinary therapy. Pt. 3: Food animal practice. Philadelphia: Saunders, 1993, 966p. cap. 18, p. 901-907.

SILVA, M.U.D., DA SILVA, E.D.F. Ceratites, ceratoconjuntivites e tumores de olhos em ovinos e caprinos, suas prováveis causas e implicações. Circular técnica. Sobral. Embrapa, v. 7, 1986.

VANDERGRAFF, R. Squamous cell carcinoma of the vulva in Merino Sheep. Aust. Vet. J. v. 52, p. 21-23, 1976 